\title{
A Modified PMV Model for Indoor Thermal Comfort Analysis: Case Study of a University Cafeteria
}

\author{
Emmanuel O.B. Ogedengbe ${ }^{1, *}$, Reuben U. Eteure ${ }^{1}$ and Marc A. Rosen ${ }^{2}$ \\ ${ }^{1}$ Energhx Research Group, Department of Mechanical Engineering, 353 Faculty of Engineering, University of Lagos, \\ Akoka, Lagos, 101017, Nigeria \\ ${ }^{2}$ Faculty of Engineering and Applied Science, University of Ontario Institute of Technology, Oshawa, L1H 7K4, \\ Ontario, Canada
}

\begin{abstract}
An energy demand load analysis of the 2001 Cafeteria complex, at the University of Lagos, with the budget of a feasible supply of biogas from a bio-degradable food waste using a downdraft bio-digester, is conducted. A walkthrough energy audit of all the appliances that are installed or operated within the complex and the thermophysical properties of the building envelope toward achieving the ASHRAE standard for thermal comfort and indoor air quality, is considered. The design and optimization process, involving collection, storage and management of the food waste from about twenty vendors operating inside the complex, is proposed. Using a standardized performance index for a conventional downdraft bio-digester, the level of dissatisfaction of occupants in each of the energy stocks within the 2001 Cafeteria is presented. The results are useful for the estimation of the economic and environmental impact assessment of a proposed development of a compact solar bio-reactor for independent generation and storage of hydrogen and the estimation of the thermal comfort of the occupants in the building, using an improved Predicted Mean Vote (PMV) model.
\end{abstract}

Keywords: Energy Stock, Demand Side Monitoring, Thermal Comfort, Predicted Percentage of Dissatisfied, Predicted Mean Vote, Air Temperature, Relative Humidity, Concentration; Occupancy.

\section{INTRODUCTION}

Recent developments in Nigeria's electricity sector underscore a significant paradigm shift in the nation's energy policy. The Electric Power Sector Reform Act, 2005 attempts to obtain a solution to the problem of energy sustainability and the promotion of clean energy. The resulting change is a shift of focus to the generation of power from renewable energy such as the use of a bio-digester. With the enormous availability of renewable resources, in addition to being one of the largest oil producing countries in the world, it is difficult to explain the fact that Nigeria's power production capacity still stands at about 4,000 MW for a population of more than 150 million. However, the power reform plan of the current administration, among other initiatives, proposes a Feed-In-Tariff (FIT) program (to be administered by the National Electricity Regulation Commission) for the generation of power with renewable energy sources. If this proposal is adopted by the major stakeholders, power producers rated with installed capacity above $1 \mathrm{MW}$ and fed into the national grid will be paid based on the technology of the renewable power project $(21.54$ cents $/ \mathrm{kWh}$ for solar photovoltaic; 7.43 cents $/ \mathrm{kWh}$ for wind; and 12.63 cents $/ \mathrm{kWh}$ for small hydro).

*Address correspondence to this author at the Energhx Research Group, Department of Mechanical Engineering, 353 Faculty of Engineering, University of Lagos, Akoka, Lagos, 101017, Nigeria; Tel: +234-703-668-9827; E-mail: ogedengbe@energhx.com
Clean energy practice starts with effective conservation of the available electricity in the local grid. However, there is little incentive for energy audits and conservation practices for most buildings in Nigeria, resulting in poor understanding of the recommended standard for indoor air quality and thermal comfort. Some of these concerns arise from observable effects on, for instance, human health, while others stem from actual or perceived environmental risks such as possible accidental release of hazardous materials. Renewable energies include wind, ocean wave and tides, solar, biomass, rivers, geothermal (heat of the earth), etc. They are 'renewable' because they are regularly replenished by natural processes and are therefore in almost endless supply. They also can operate without polluting the environment. Technologies have been developed to harness these energies and such technologies are called renewable energy technologies (RETs) or "clean energy technologies" or "green energy technologies". Because renewable energy resources are constantly being replenished from natural sources, they have security of supply, unlike fossil fuels, which are negotiated on the international market and subject to international competition, sometimes resulting in conflicts and shortages. A global effort towards demand side management has been reported by the International Energy Agency [1]. Fig. (2) shows three basic models for improving building energy efficiency, including Solar Energy Supply Contracting (Solar-ESC), Energy Supply Contracting (ESC) and Energy Performance Contracting (EPC). While the basic models have some challenges, a search for a suitable "tool" to exe- 


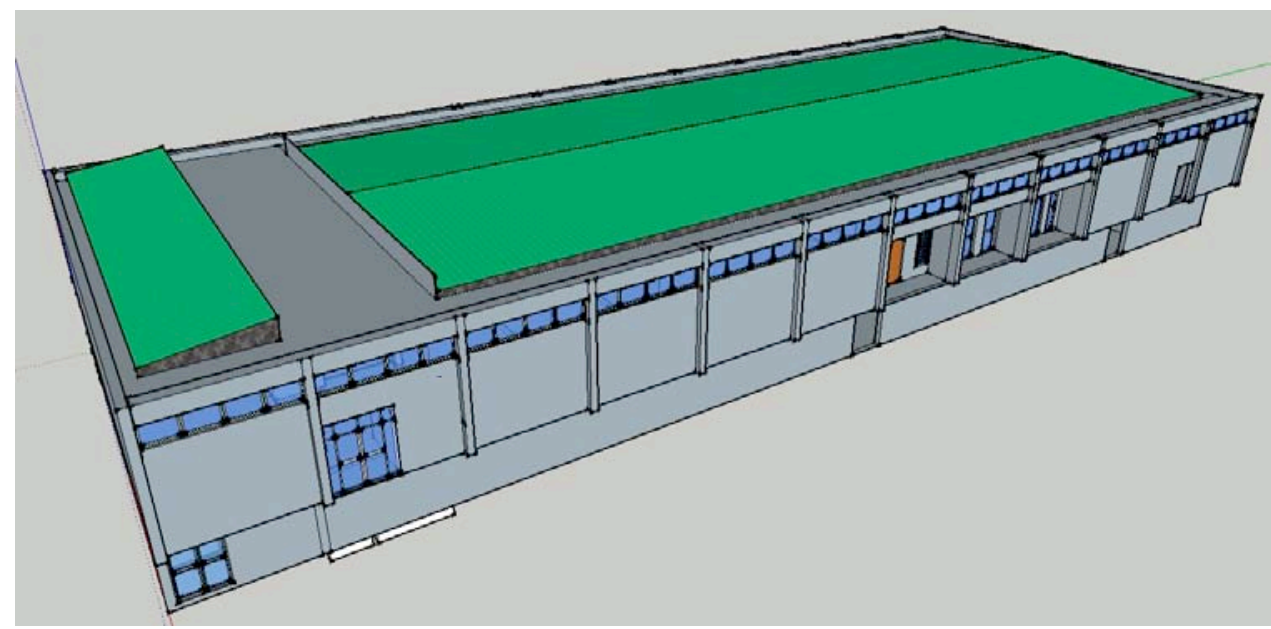

Fig. (1). 2001 University Cafeteria Complex.

cute energy conservation potentials has led to the recommendation of an integrated Energy-Contracting model [2].

The University of Lagos, Akoka-Yaba, Lagos (UNILAG) is one of the foremost federal universities located in the western part of Nigeria and was founded in 1962. The presence of the university in Lagos, which is the commercial nerve centre of Nigeria, has caused the institution to grow notably. The student population has continued to increase with a corresponding increase in teaching and non-teaching staff. Banks and agro-allied industries are now scattered within and outside the university. A fraction of the electrical power supplied to the University of Lagos is distributed to staff quarters, hostels, offices, lecture halls, faculty blocks, laboratories and workshops, shopping malls, etc., and subsequently used to power lighting systems, sound systems, kitchens, fridges, air conditioners, fans, electric kettles, computers and other household/office devices. This fraction of power does not meet the $8 \mathrm{MW}$ power demand of the university community. The university administration continuously spends millions of Naira each year to supplement power from the Power Holding Company of Nigeria (PHCN).

Energy consumption results from thermal and electricity demands of the building, while the supply of energy to the building can either in form of electricity energy distributed from the national grid or from any source of renewable energy. Adelaja et al. [3] carried a survey on the energy consumption in UNILAG. It was reported that much of the electricity consumption is utilized to power the air conditioning system, which are used to overcome indoor thermal discomfort during harsh season. They also stated four major strategies for reducing peak demand such as: load reducing strategies, high efficiency equipment, energy source substitution and on site heat and electricity generation. Energy efficient mechanism is a way to utilize the available energy properly by ensuring that the supply of the energy meets the required demand of the occupant. Ogedengbe et al. [4] conducted a demand side monitoring of residential and commercial facilities in the city of Ottawa and city of Guelph. An effective engineering tool was generated as an independent forecasting model for each energy stocks. They proposed an enhanced energy system efficiency which is projected to lead to economic and environmental saving advantages. Also, Etiosa [5] carried out a study to identify low cost ways of reducing energy consumption and gave two important ways to approach the efficient use of energy, which are the technological approach and the behavioral approach. It was proposed that renewable energy and energy efficiency are two components which if integrated into the energy policy of Nigeria for sustainable energy development and with energy efficiency; the nation can save over 50 percent of the present energy consumed.

In this study, we audit the feasibility of developing and demonstrating a bio-digester system, by using food waste from the operation of vendors at the 2001 Cafeteria complex, conduct a comprehensive energy audit of the complex; and estimate the loads for the management of the indoor air quality, electrical appliances and thermal comfort demand of the building using an improved PMV model, while monitoring and characterizing the food waste that will be fed into the proposed bio-digester system.

\section{DESCRIPTION OF THE ENERGY SYSTEM}

In classical thermodynamics, domestic and non-domestic facilities, like the 2001 Cafeteria complex in Fig. (1), are considered as energy systems. The demand for energy includes lighting, ventilation and air-conditioning, and appliances. Without energy storage, renewable power supply from solar photovoltaic technology will depend on the national grid for consistent power supply. Therefore, accurate energy planning requires an analysis of the demand for power. An energy system control volume comprises the external boundary of a building envelope. Fig. (2) shows the schematic of a bio-digester with various compartments for drying, pyrolysis, and gasification of the food waste. The design and integration of the bio-digester depend on an accurate analysis of the demand for energy to maintain a smooth running of the cafeteria complex. These activities include space cooling, cooking, entertainment, and processing of goods and services, depending on the nature of business of the vendors. The boundary of this building envelope encloses a mass of fluid, representing transport of heat and fluid transport with significant energy conversion mechanisms. Assuming incompressible flows, these scalar transport variables can be predicted based on the following three-dimensional form of continuity, momentum, $\mathrm{CO}_{2}$ concentration, and energy equations: [6] 


\section{Downdraft Gasifier}

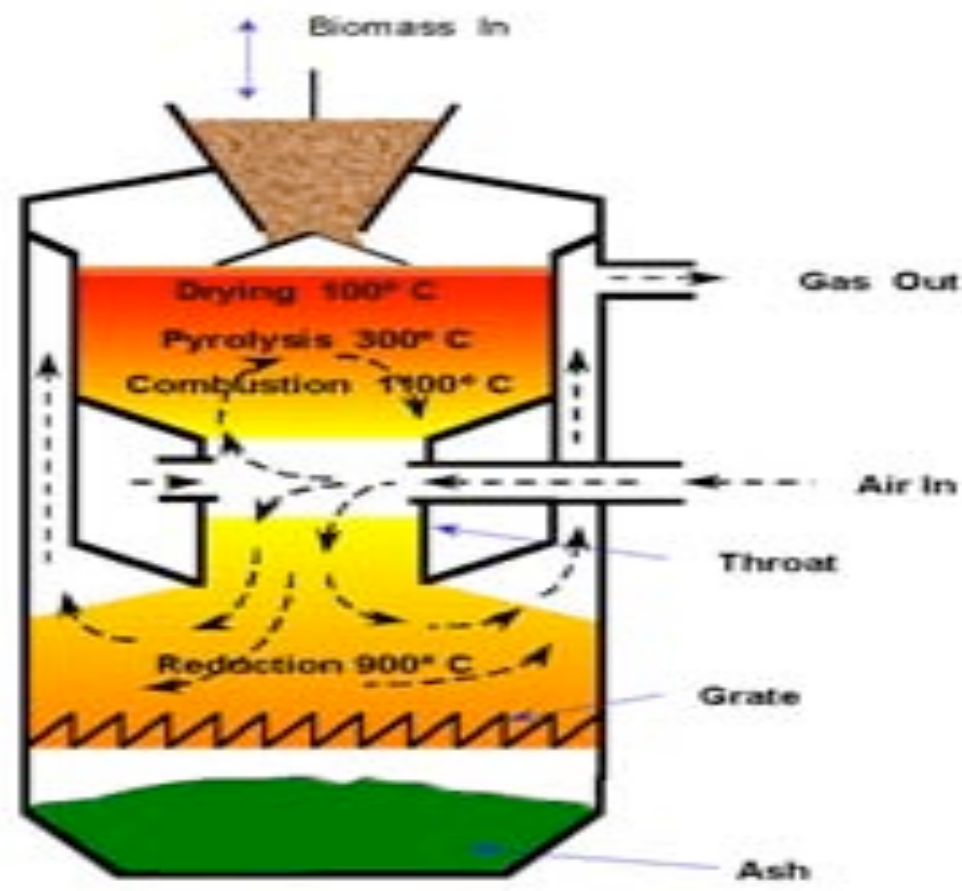

Fig. (2). Schematic of a bio-digester.
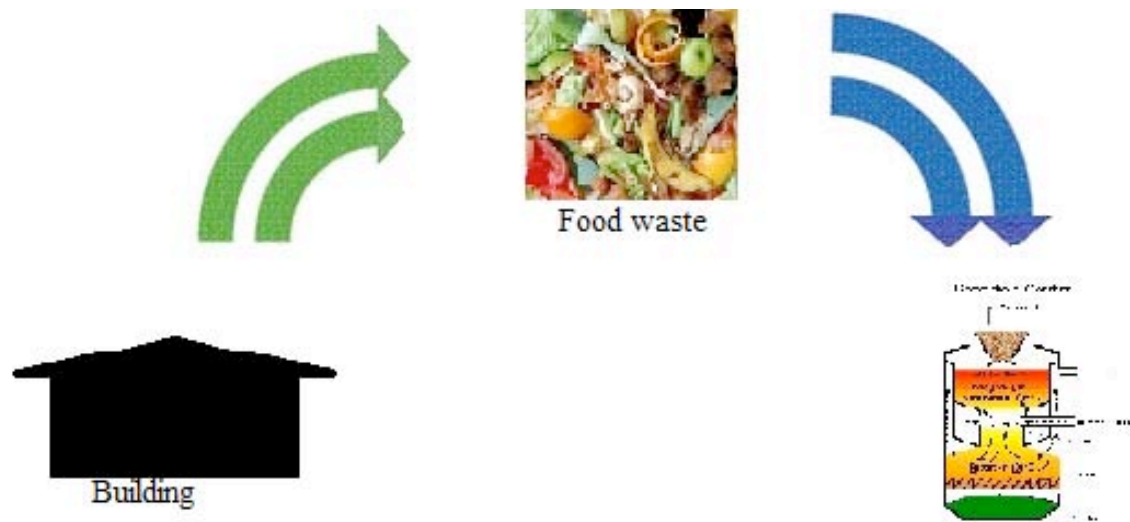

Building

Food waste

downdraft gasifier
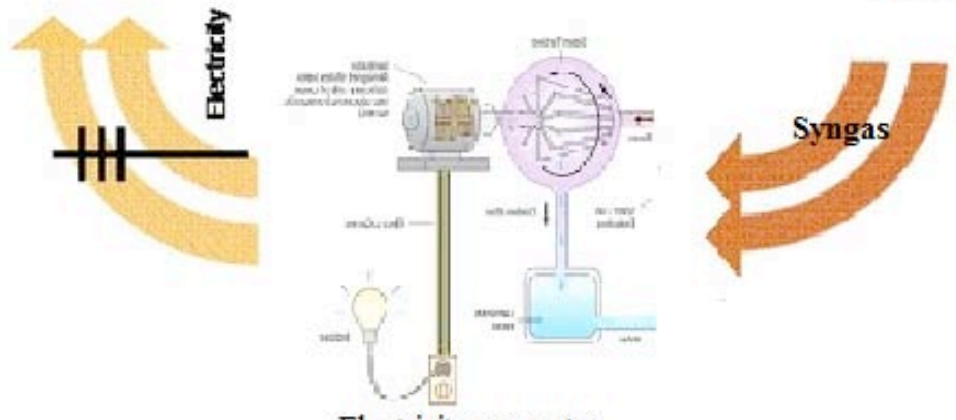

Electricity generator

Fig. (3). Schematic showing the integration of a bio-digester system with the cafeteria complex.

$$
\begin{aligned}
& \frac{\partial(\rho)}{\partial t}+\frac{\partial(\rho U)}{\partial x}+\frac{\partial(\rho V)}{\partial y}+\frac{\partial(\rho W)}{\partial z}=0 \\
& \frac{\partial(\rho U)}{\partial t}+\nabla \cdot(\rho v U)=-\frac{\partial P}{\partial x}+\nabla \cdot(\mu \nabla U)+S_{U} \\
& \frac{\partial(\rho V)}{\partial t}+\nabla \cdot(\rho v V)=-\frac{\partial P}{\partial y}+\nabla \cdot(\mu \nabla V)+S_{V}
\end{aligned}
$$$$
\frac{\partial(\rho W)}{\partial t}+\nabla \cdot(\rho v W)=-\frac{\partial P}{\partial z}+\nabla \cdot(\mu \nabla W)+S_{W}
$$$$
\text { (2) } \frac{\partial\left(\rho c_{p} T\right)}{\partial t}+\nabla \cdot\left(\rho c_{p} v T\right)=\nabla \cdot(k \nabla T)
$$$$
\text { (3) } \frac{\partial\left(\rho c_{p} C\right)}{\partial t}+\nabla \cdot\left(\rho c_{p} v C\right)=\nabla \cdot(k \nabla C)
$$ 


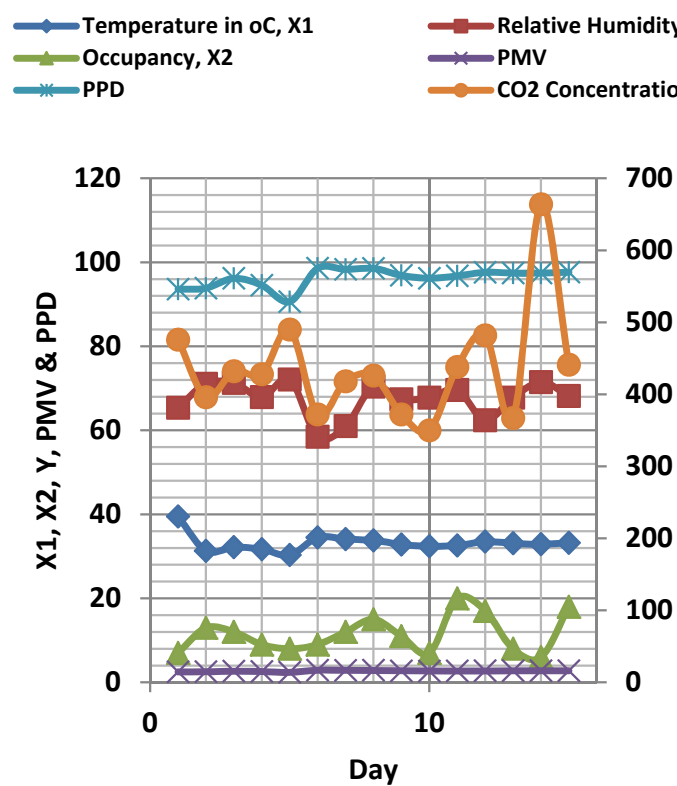

(a)

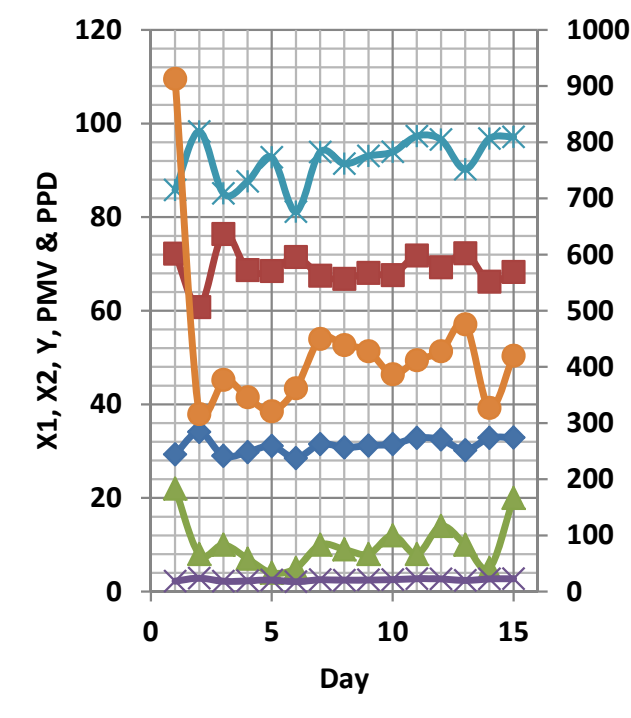

(b)

Fig. (4). Indoor RH, temperature, occupancy and $\mathrm{CO}_{2}$ concentration for Husky Foods in the (a) morning; and (b) afternoon (The horizontal axis depicts the days, while the primary vertical axis depicts the temperature in degrees Celsius, relative humidity in \%, occupancy, PMV and PPD; while the secondary vertical axis shows the $\mathrm{CO}_{2}$ concentration in PPM).

The energy system has a volume whose boundary encloses the contained mass; within the system there is variation in the indoor air concentration and the temperature. The density of the system is constant since it is assumed to be incompressible. The source terms in Eqns. 2-4 represent the various heat sources within the complex, including the heat releases from cooking appliances and human activities.

Fig. (3) shows a schematic of the renewable supply of bio-fuel for the bio-digester system. The heat of combustion is also proposed to be supplied by a renewable source, i.e., a photocatalytic reactor. However, a good estimation of the quantity of available food waste is essential in order to ascertain the effectiveness of the proposed renewable energy system. The method of collection and processing of food waste can be a significant design criteria. For instance, the moisture content of the feedstock plays a vital role in the design of the drying chamber configuration and all the heat transfer components of the system [7]. The thermophysical properties of the complex are shown in Table 1. There are ten vendors providing various goods and services, providing cybercafe, restaurant, retailing, processing of consumables and the production of entertainment services within the complex, namely Husky Foods, Unilag Water, Hommies Bakery, Eatery Hall, Wisdom Cafe, Pinto Lounge, Oriental Cuisine, PMG Supermarket, PMG Food, and PMG Cafe. As observed in Figs. (4-12), the indoor air quality and thermal comfort level of these various compartments differ.

\section{PMV MODEL FOR THERMAL COMFORT ANALYSIS}

The Predicted Mean Vote model uses heat balance principles to relate the six key factors for thermal comfort to the average response of people on the thermal sensation scale. Orosa [8] established that the thermal comfort rates of an environment can be found based on the study of thermal bal- ance of the human body. The comfort equation is obtained by setting the heat balance in thermally comfortable conditions for an individual. PMV is a well known example of a thermal comfort performance indicator, developments are found in higher resolution indicators, applying e.g. thermophysiological models $[9,10]$. The ASHRAE thermal sensation scale, which was developed for use in quantifying people's thermal sensation, is defined as shown in Table $\mathbf{2}[11,12]$.

This scale presumes that people voting $+2,+3,-2$, or -3 on the thermal sensational scale are dissatisfied and the simplification that Predicted Percentage of Dissatisfied (PPD) is symmetric around the neutral PMV. It is well known that environmental factors influence human comfort in a building [13, 14]. The general comfort equation developed by Fanger [15] to describe the conditions for which a large group of people will feel thermal neutrality is too complex and often cannot be used in real time applications [16]. The PMV index can be determined when the metabolic rate and the clothing insulation are estimated and the environmental parameters of air temperature and relative humidity are measured. The PMV can be calculated by the following relations [17]:

$P M V=$

$\left(0.028+0.3033 e^{-0.036 M}\right)\{(M-W)-3.05[5.733-0.000699(M-W)-$

$P a]-0.42[(M-W)-58.15]-0.0173 M(5.867-P a)-0.0014 M(34-$

$\left.T a)-3.96 \times 10^{-8} F_{c l}\left[\left(T_{c l}+273\right)^{4}-\left(T_{m r t}+273\right)^{4}\right]-F_{c l} h_{c}\left(T_{c l}-T_{a}\right)\right\}$

Here,

$$
\begin{aligned}
& T_{c l}=35.7-0.028(M-W)-0.155 I_{c l}\left\{3.96 \times 10^{-8} F_{c l}\left[\left(T_{c l}+273\right)^{4}-1\right.\right. \\
& \left.\left(T_{m r t}+273\right)^{4}\right] \\
& \left.-F_{c l} h_{c}\left(T_{c l}-T_{a}\right)\right\}
\end{aligned}
$$


Table 1. Thermo-physical Properties of Building Envelope Elements.

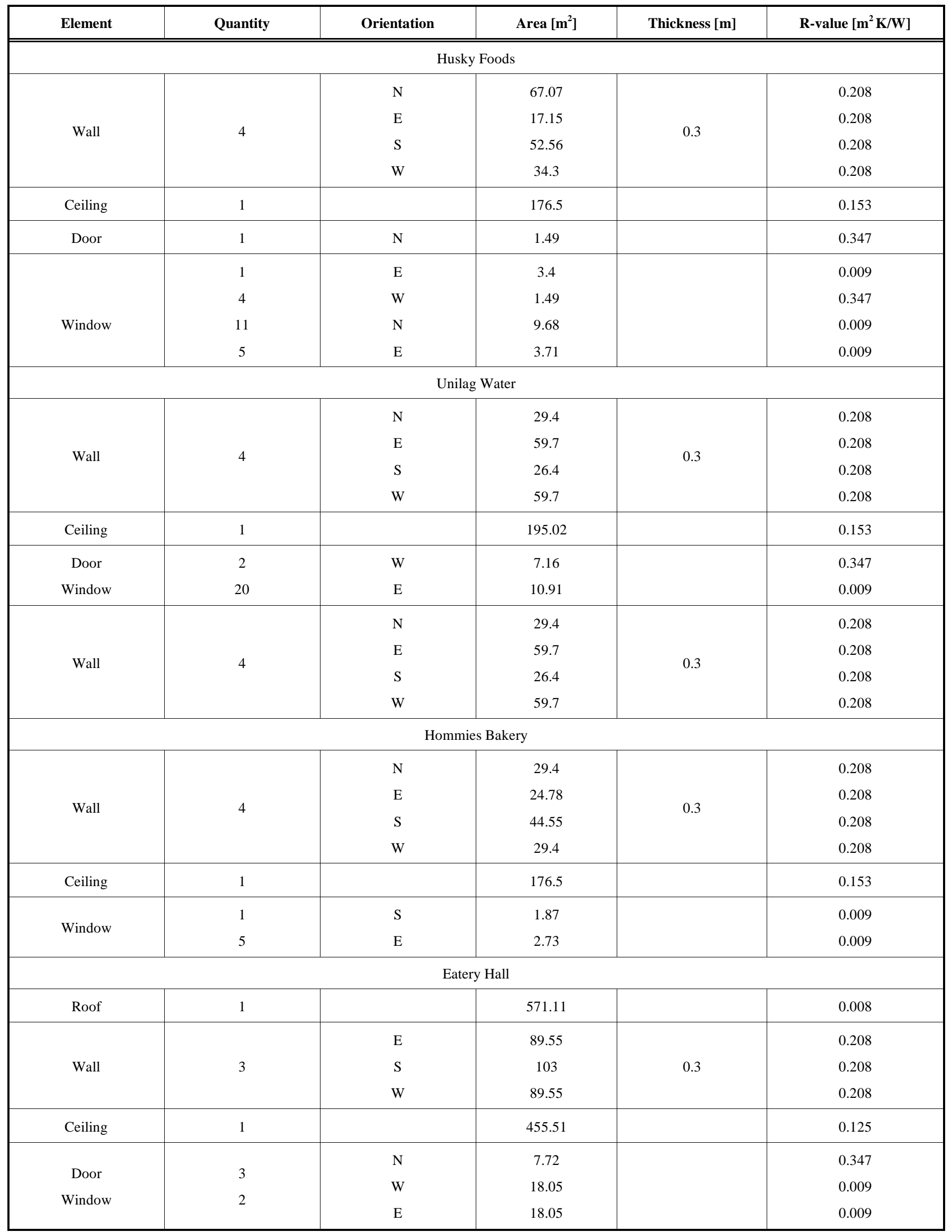


Table 1. contd...

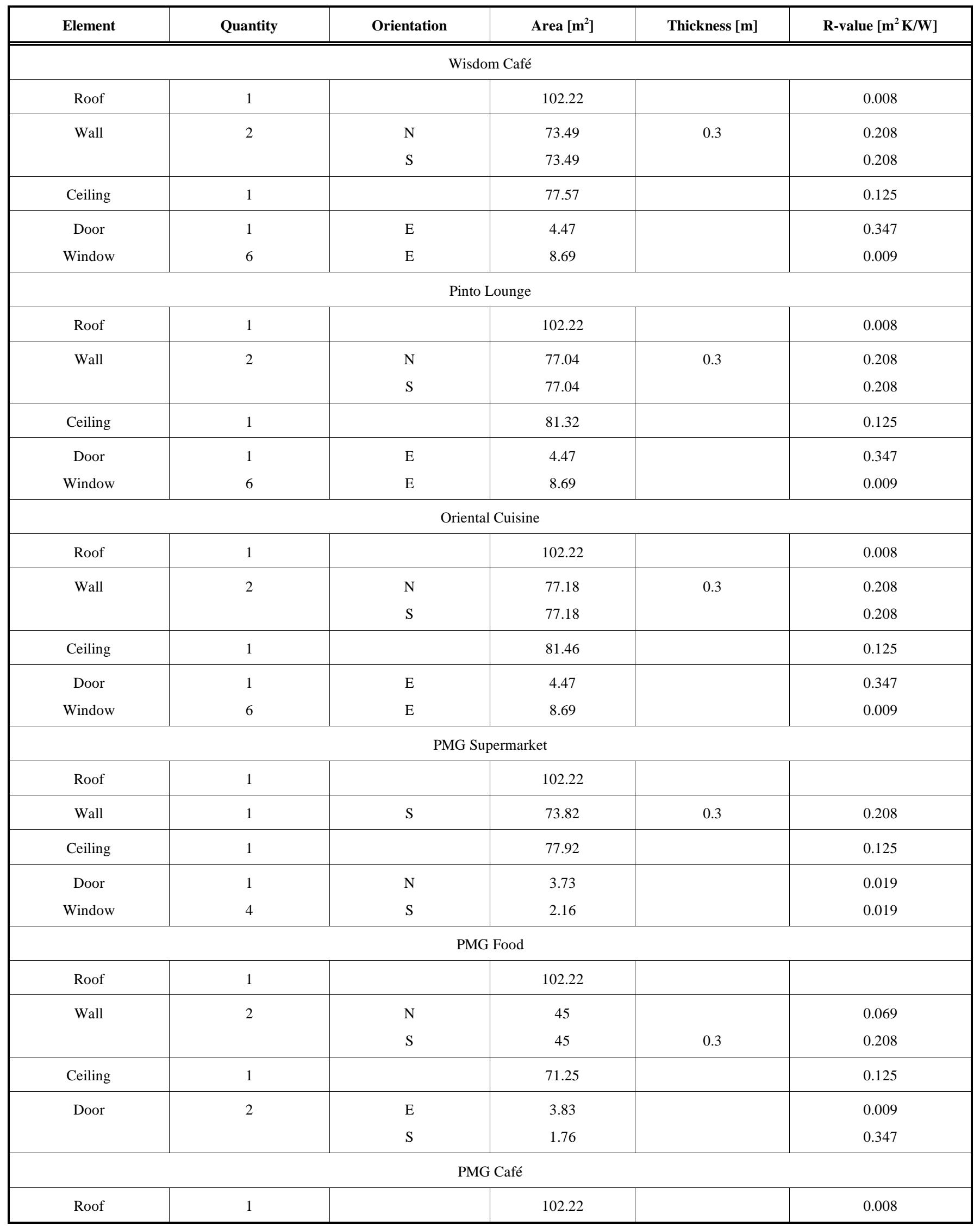


Table 1. contd...

\begin{tabular}{|c|c|c|c|c|c|}
\hline Element & Quantity & Orientation & Area $\left[\mathrm{m}^{2}\right]$ & Thickness [m] & $R$-value $\left[\mathrm{m}^{2} \mathbf{K} / \mathrm{W}\right]$ \\
\hline \multirow[t]{2}{*}{ Wall } & \multirow[t]{2}{*}{2} & $\mathrm{~N}$ & 77.04 & \multirow[t]{2}{*}{0.3} & 0.208 \\
\hline & & S & 77.04 & & 0.208 \\
\hline Ceiling & 1 & & 76 & & 0.125 \\
\hline Door & 1 & S & 1.97 & & 0.347 \\
\hline
\end{tabular}

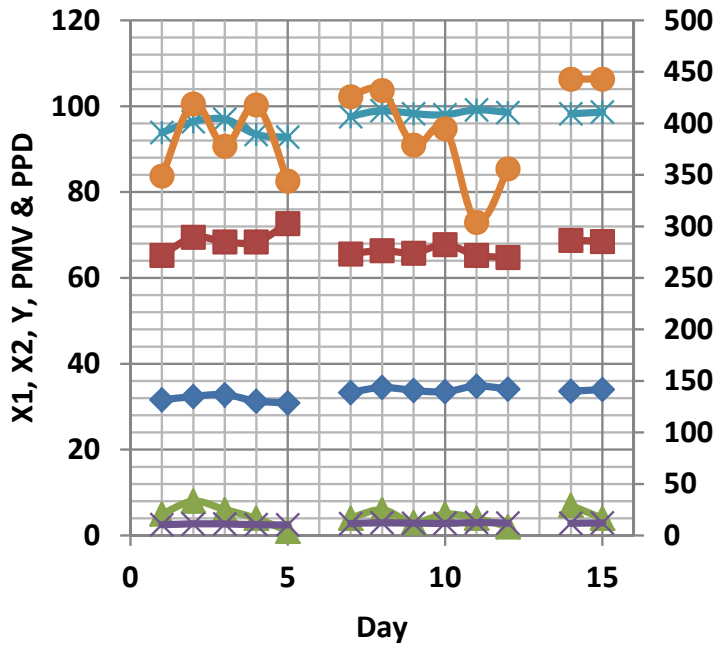

(a)

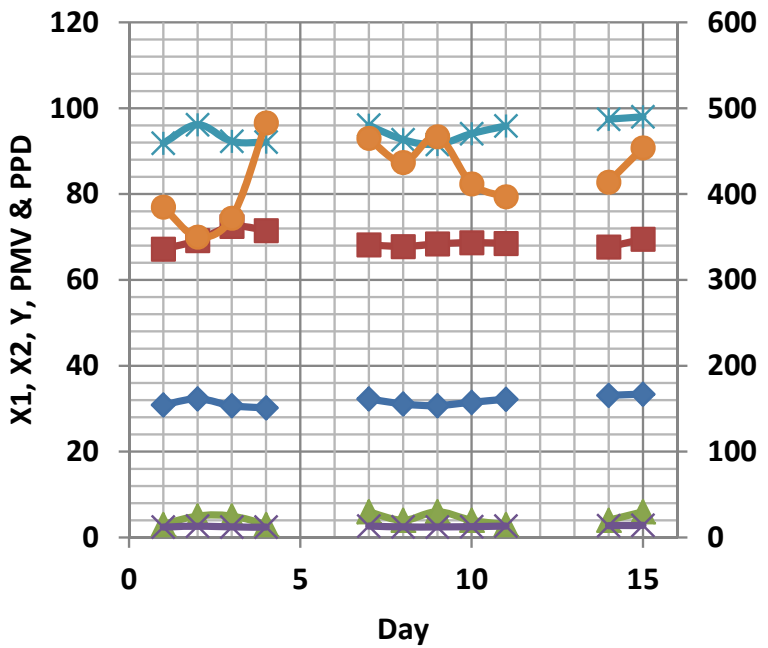

(b)

Fig. (5). Indoor $\mathrm{RH}$, temperature, occupancy and $\mathrm{CO}_{2}$ concentration for Unilag Water in the (a) morning; and (b) afternoon. Other details are as in Fig. (4).

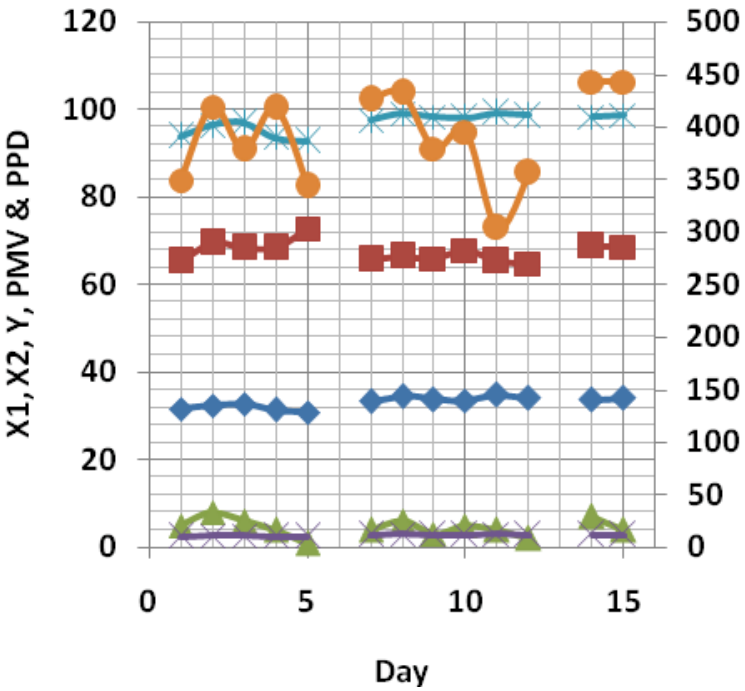

(a)

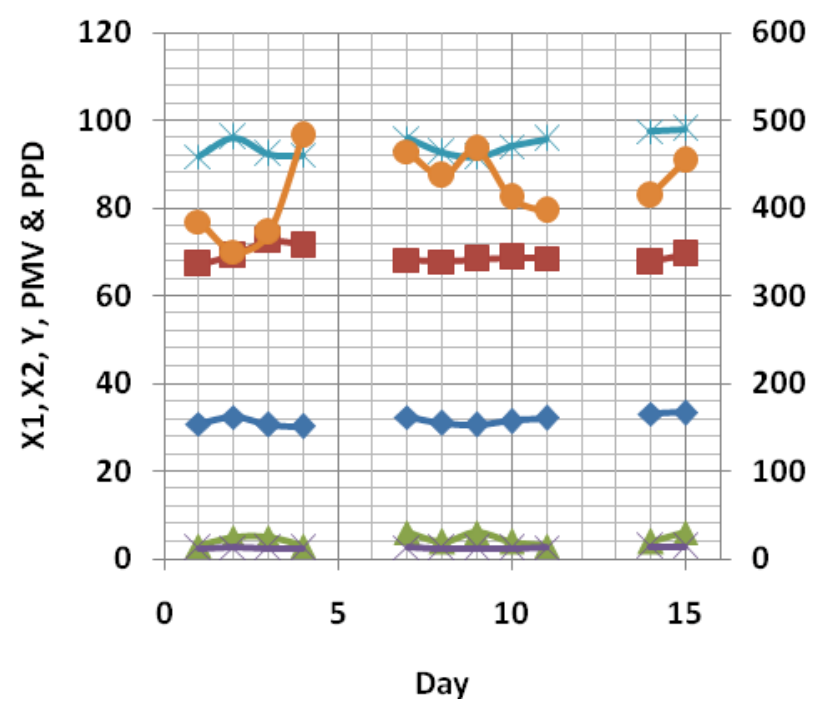

(b)

Fig. (6). Indoor $\mathrm{RH}$, temperature, occupancy and $\mathrm{CO}_{2}$ concentration for Hommies Bakery in the (a) morning; and (b) afternoon. Other details are as in Fig. (4). 


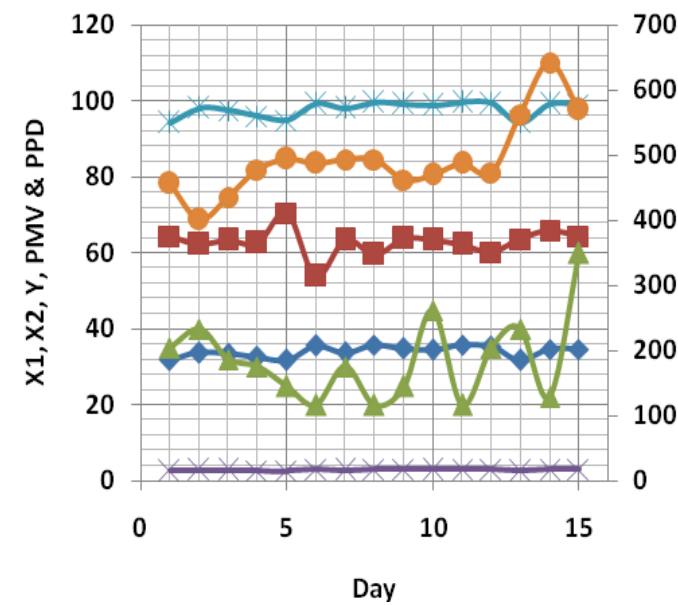

(a)

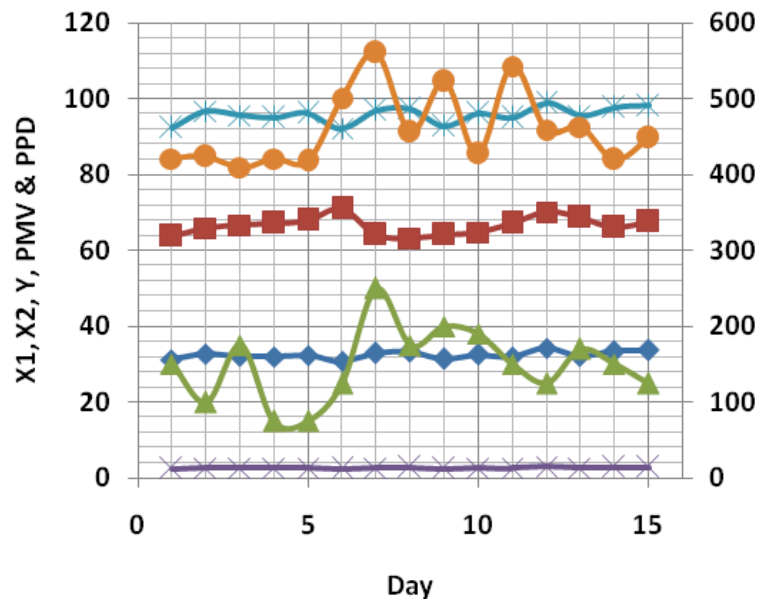

(b)

Fig. (7). Indoor $\mathrm{RH}$, temperature, occupancy and $\mathrm{CO}_{2}$ concentration for Eatery Hall in the (a) morning; and (b) afternoon. Other details are as in Fig. (4).

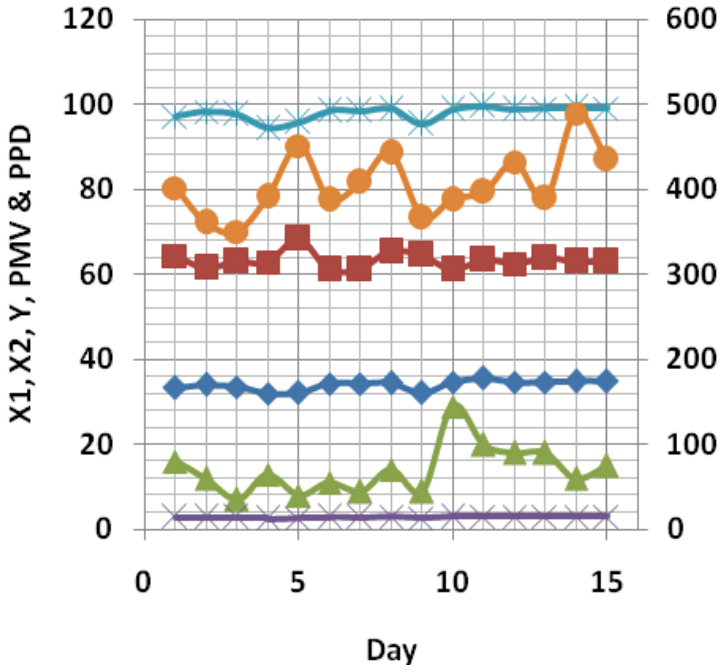

(a)

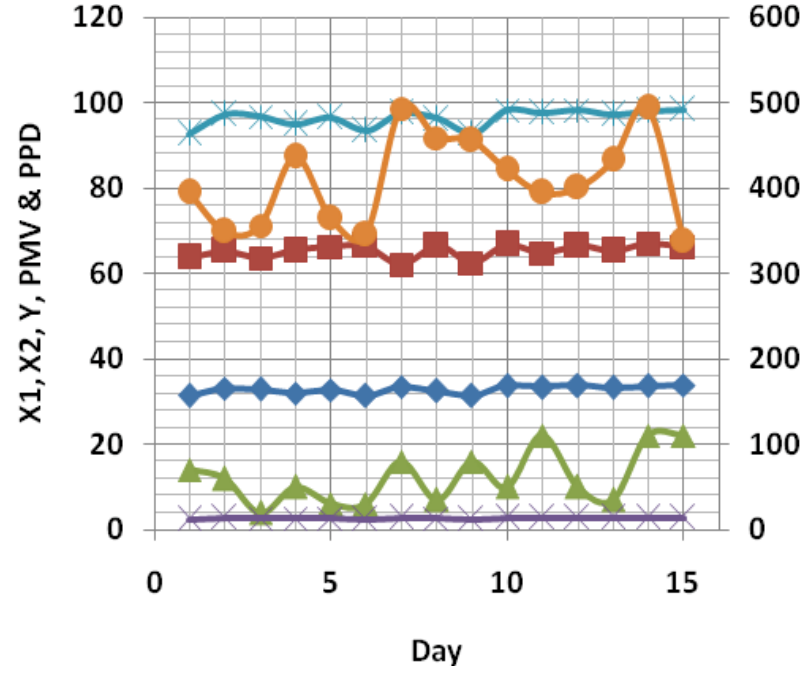

(b)

Fig. (8). Indoor RH, temperature, occupancy and $\mathrm{CO}_{2}$ concentration for Wisdom Cafe in the (a) morning; and (b) afternoon. Other details are as in Fig. (4).

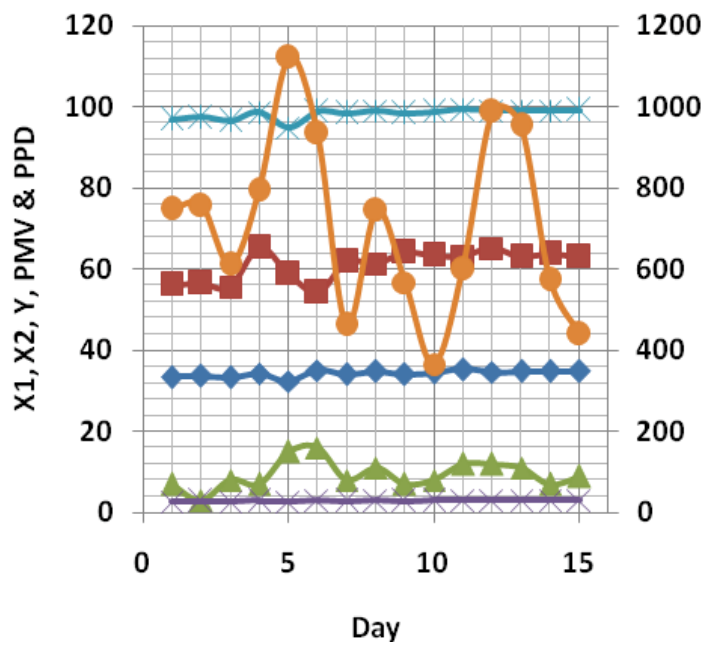

(a)

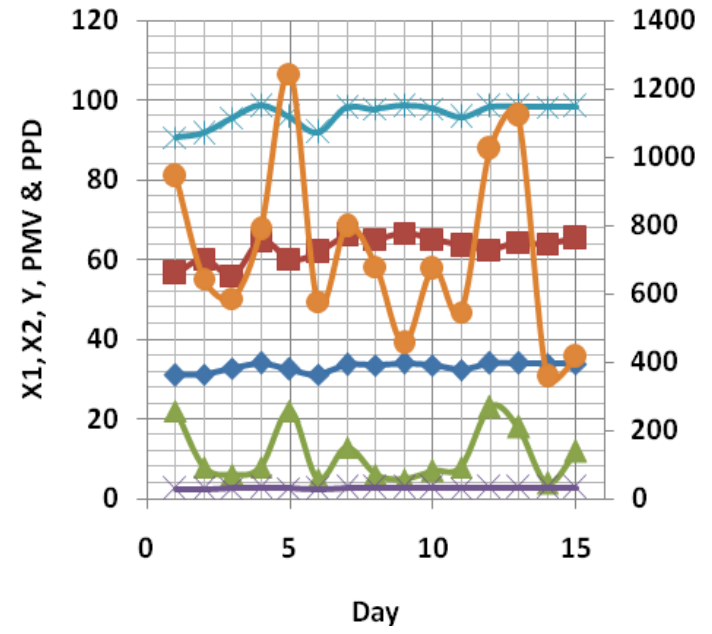

(b)

Fig. (9). Indoor $\mathrm{RH}$, temperature, occupancy and $\mathrm{CO}_{2}$ concentration for Pinto Lounge in the (a) morning; and (b) afternoon. Other details are as in Fig. (4). 


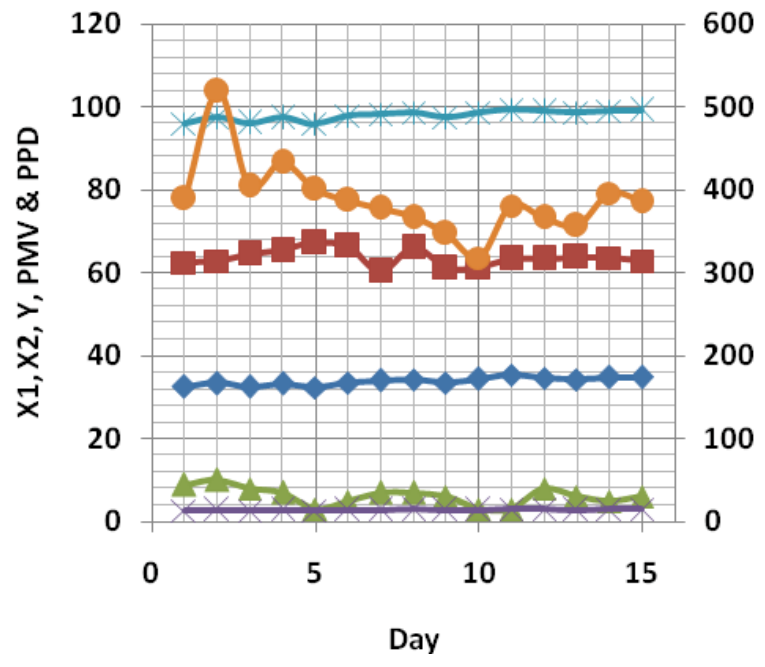

(a)

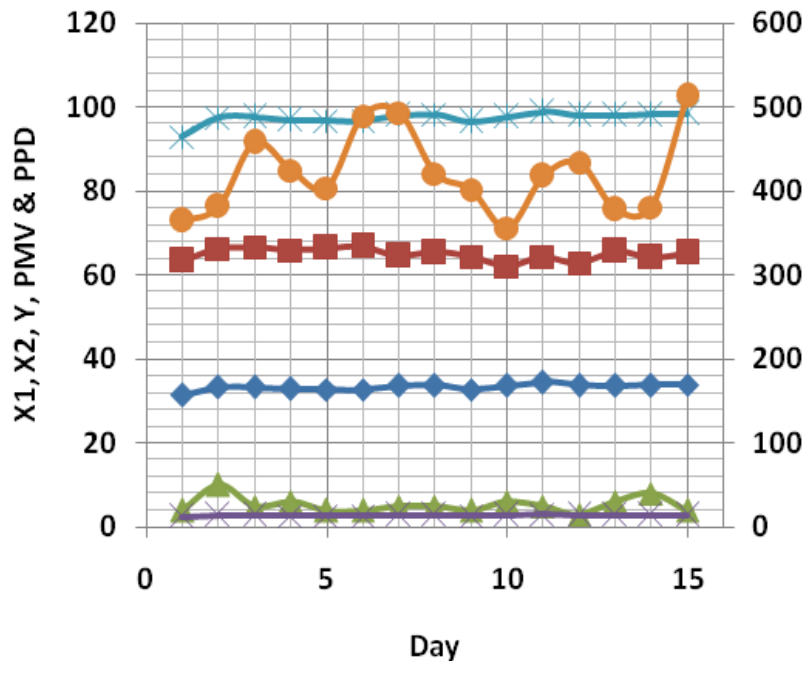

(b)

Fig. (10). Indoor RH, temperature, occupancy and $\mathrm{CO}_{2}$ concentration for Oriental Cuisine in the (a) morning; and (b) afternoon. Other details are as in Fig. (4).

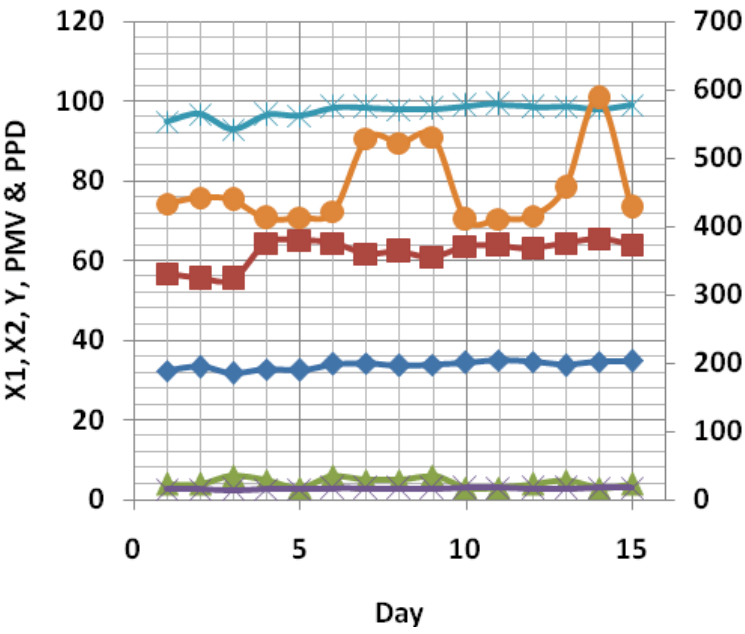

(a)

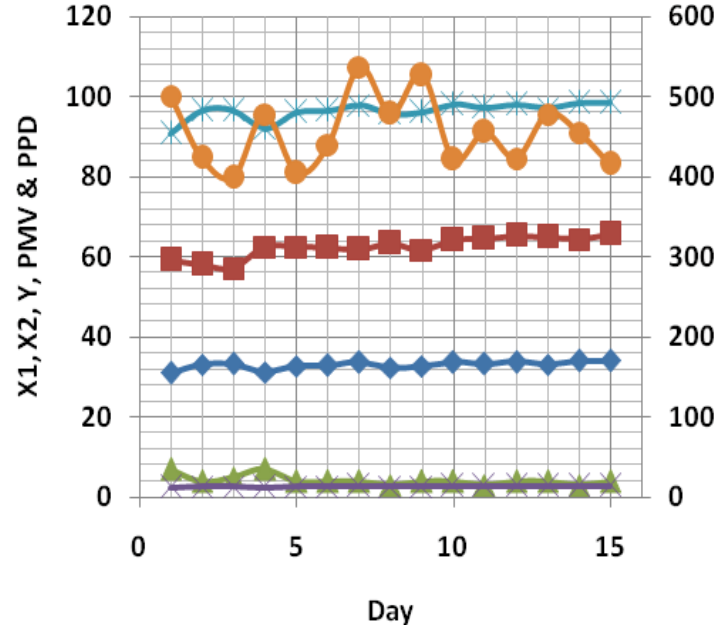

(b)

Fig. (11). Indoor RH, temperature, occupancy and $\mathrm{CO}_{2}$ concentration for PMG Supermarket in the (a) morning; and (b) afternoon. Other details are as in Fig. (4).

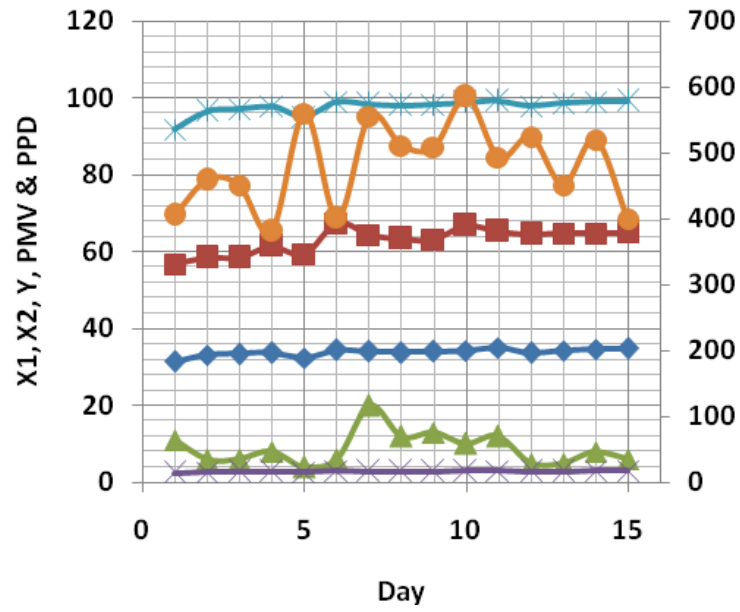

(a)

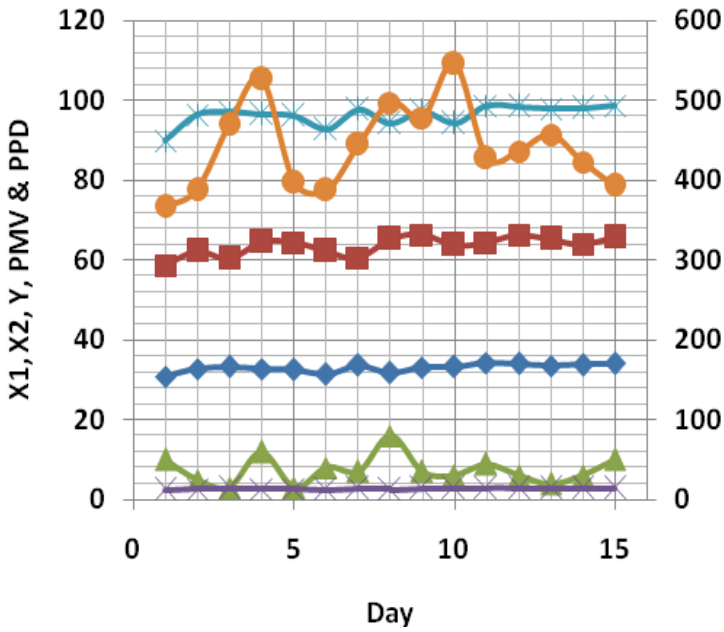

(b)

Fig. (12). Indoor RH, temperature, occupancy and $\mathrm{CO}_{2}$ concentration for PMG Food in the (a) morning; and (b) afternoon. Other details are as in Fig. (4). 
Table 2. PMV Index (Thermal Sensation Scale)

\begin{tabular}{|c|c|c|c|c|c|c|}
\hline $\mathbf{+ 3}$ & $\mathbf{+ 2}$ & $\mathbf{+ 1}$ & $\mathbf{0}$ & $\mathbf{- 1}$ & $\mathbf{- 2}$ & $\mathbf{- 3}$ \\
\hline \hline Hot & Warm & Slightly warm & Neutral & Slightly cool & Cool & Cold \\
\hline
\end{tabular}

Table 3. Regression Coefficients of the Cafetaria's Energy Stocks

\begin{tabular}{|c|c|c|c|c|c|c|c|c|}
\hline \multirow{2}{*}{$\begin{array}{c}\text { Energy Stocks } \\
\text { i } \\
\text { Husky }\end{array}$} & \multicolumn{8}{|c|}{ Sensitivity Coefficients } \\
\hline & \multicolumn{2}{|c|}{$\mathbf{a}_{0}$} & \multicolumn{2}{|c|}{$\mathbf{a}_{1}$} & \multicolumn{2}{|c|}{$\mathbf{a}_{2}$} & \multicolumn{2}{|c|}{$\mathbf{a}_{3}$} \\
\hline Unilag water & 11.08 & 0.27 & 0.0049 & 2.32 & 0.00032 & 0.0012 & 6.61 & -1.39 \\
\hline Homes bakery & 32.28 & 0.19 & 0.011 & 1.9 & 0.001 & 0.025 & 6.49 & -0.396 \\
\hline Wisdom cafe & 64.66 & 48.22 & 0.00013 & 0.61 & -0.000002 & -0.0058 & -0.108 & -0.0435 \\
\hline Pintos lounge & 62.12 & -0.70 & -0.0004 & 1.97 & 0.0000036 & -0.00043 & -0.113 & -0.12 \\
\hline Oriental cuisine & 64.68 & 78.36 & 0.00015 & -0.727 & -0000037 & 0.02 & -0.16 & 0.417 \\
\hline PMG super & 66.15 & 43.77 & 0.00008 & 0.56 & 0.0000067 & 0.0068 & -0.93 & -0.68 \\
\hline
\end{tabular}

$h_{c}=\left\{\begin{array}{c}2.38\left(T_{c l}-T_{a}\right)^{0.25} \text { for } 2.38\left(T_{c l}-T_{a}\right)^{0.25} \geq 12.1 \sqrt{V_{a r}} \\ 12.1 \sqrt{V_{a r}} \text { for } 2.38\left(T_{c l}-T_{a}\right)^{0.25} \leq 12.1 \sqrt{V_{a r}}\end{array}\right.$

$F_{c l}=\left\{\begin{array}{l}1.00+1.290 \times I_{c l} \text { for } I_{c l}<0.078 m^{2}{ }^{\circ} \mathrm{CW}^{-1} \\ 1.05+0.645 \times I_{c l} \text { for } I_{c l}>0.078 \mathrm{~m}^{2}{ }^{\circ} \mathrm{CW}^{-1}\end{array}\right.$

$V_{a r}=V_{Q}+0.005\left(M / A_{D U}-58.15\right)$

$\left.P a=R H \times 10 \times e^{(16.6536-4030.183} / T_{a}+235\right)$

The equation for predicted percentage dissatisfied (PPD) is given as follows [11]:

$P P D=100-95 \exp \left(-0.03353 P M V^{4}+0.2179 P M V^{2}\right)$

A PPD less than $20 \%$ is good since it is considered to satisfy $80 \%$ of the occupants. However, due to the dynamic response of the environment to changes in occupancy, dynamic model that is capable of smart response to the environment is proposed in this study. The improved PMV uses several predictor variables for smart response, including the $\mathrm{CO}_{2}$ concentration, the occupancy of the energy stock in addition to other variables for determining the PMV of the energy stock, as follows:

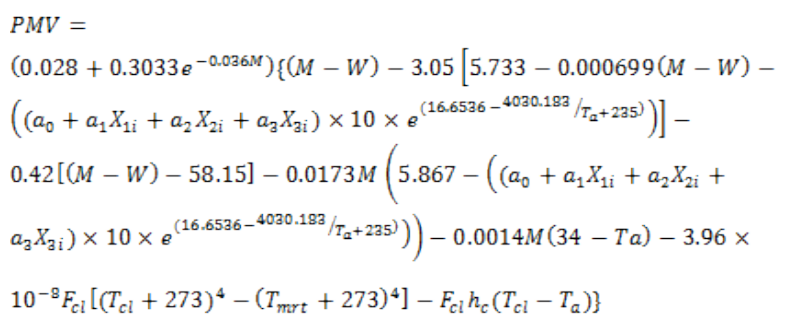

Note that $\mathrm{X}_{1}=\mathrm{T}_{\mathrm{a}}=$ air temperature.

\section{RESULTS AND DISCUSSION}

Proposing a three-predictor-variable regression analysis, including the indoor concentration of $\mathrm{CO}_{2}$, occupancy, and indoor temperature, the thermal comfort of the energy stocks can be captured, using the relative humidity data; while a one-predictor model, based on the number of electrical appliances is used for the forecast of electrical power consumption. The forecast of electricity consumption and thermal comfort for the cafeteria complex represents a significant planning tool for the proposed independent power generation in order to mitigate the problem of erratic power supply from the grid. The generalized polynomial regression analysis suggests that either the relative humidity or electrical power consumption is the criterion variable, for each of the energy stocks. Using the thermo-physical properties of the energy stock (as shown in Fig. 1), the facility characterisation is geared towards the forecast of energy energy consumption.

Figs. (4 to 12) show the $\mathrm{CO}_{2}$ concentration of the energy stock on the secondary vertical axis, while the other data are plotted on the primary vertical axis. These figures show that the $\mathrm{CO}_{2}$ concentration increases as the occupancy of the energy stock rises. However, as the indoor temperature of the energy stock increases, the relative humidity of the energy stock decreases. PPD appears significantly affected by the number of occupants within the energy stocks. However, significant level of dissatisfaction is observed in Husky Food, compared with other energy stocks during the period of the investigation. The following equation predicts the relative humidity, $R H_{i}$, for all the energy stocks within the complex, including Husky foods, Unilag water, Hommies 


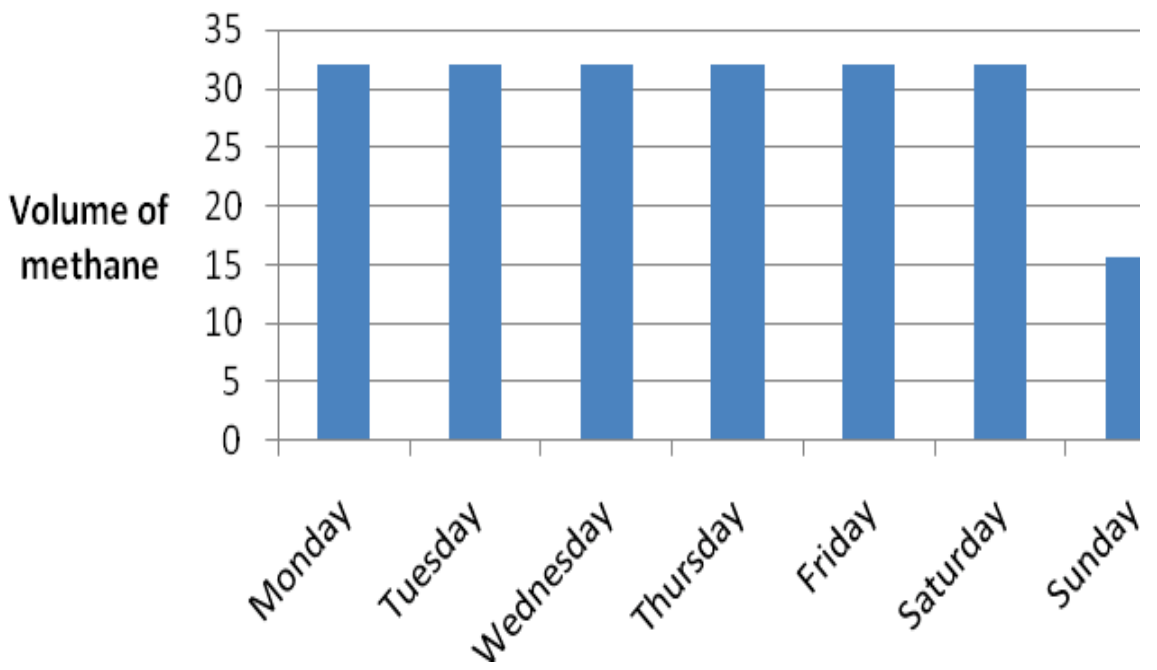

Fig. (13). Estimated Volume of Daily Methane Production in $\mathrm{m}^{3}$.

bakery, Eatery hall, Wisdom cafe, Pinto lounge, Oriental cuisine and PMG:

$Q_{i}=a_{i 0}+\sum_{j=1}^{m} a_{i j} X_{i j}, i=1,2,3, \ldots n$

where $n$ represents total number of energy stocks, $X_{i j}$ denotes the predictor variables, and the regression coefficients are denoted by $a_{i j}$. For instance in the case of thermal comfort analysis, the following are the predictor variables: $X_{1}$ is the indoor temperature, $X_{2}$ is the $\mathrm{CO}_{2}$ concentration and $X_{3}$ is the occupancy of the energy stock, and the criterion variable is the relative humidity of the energy stock.

Table 3 shows the results of the regression coefficients based on Eqn. (15). These coefficients are related to the sensitivity coefficients established in the PMV models of previous investigators [18, 19]. Like other adaptive models $[20,21]$, the subjectivity of the thermal correlations of the proposed model and the interpretations flowing from a complex interaction between the occupants of the 2001 university cafetaria provides the theoretical underpinning to the approach of the thermal comfort studies.

Mansour [22] estimated that $10 \mathrm{~kg}$ of kitchen waste produces $1.5 \mathrm{~m}^{3}$ of biogas, which consists of $1 \mathrm{~m}^{3}$ of methane. Fig. (13) depicts the estimated volume of daily methane production from the 2001 University Cafeteria, based on the same model. This implies that $319.77 \mathrm{~kg}$ of the food waste daily will produce $31.97 \mathrm{~m}^{3}$ of methane daily from Monday to Saturday, while on Sunday $150.48 \mathrm{~kg}$ of food waste will produce $15.48 \mathrm{~m}^{3}$ of methane, resulting in an estimated monthly methane production of $200 \mathrm{~m}^{3}$.

\section{CONCLUSIONS}

Analyses are presented of the energy demand in Nigeria's emerging electricity market and the potential is described of not using fossil fuels, but rather using renewable energy sources of high potential. A multivariate energy consumption model is proposed as a significant criteria for the design of subsystems, including a bio-digester, a waste food collector and a mixer, a bio-reactor, and a hydrogen storage system. The proposed biogester will produce an estimated $200 \mathrm{~m}^{3}$ of methane gas monthly from food waste collected from a cafetaria at the University of Lagos, which is assessed. All the energy stock has PMV index greater than 2, which indicates dissatisfaction regarding human comfort. With adequate monitoring of the characteristics of each energy stock, through the analysis of the regression variables, demand monitoring of the energy needs and thermal comfort of all clients is possible. A calibration of the client's energy demand with the coefficients of the regression analysis is possible and, together with the use of the estimated quantity of methane to overcome the thermal dissatisfaction of the occupants in the complex, the demand of energy from the national grid will be reduced significantly.

\section{CONFLICT OF INTEREST}

The authors confirm that this article content has no conflicts of interest.

\section{ACKNOWLEDGEMENTS}

Declared none.

\section{REFERENCES}

[1] IEA DSM Task XVI - Competitive Energy Services (EnergyContracting, ESCo Services), Final Task Report, Phase 1, 20062009, Graz, 2010.

[2] Integrated Energy Contracting. A New ESCo Model to Combine Energy Efficiency and Renewable Supply in Large Building and Industry, Final Task Report, Phase 1 2006-2009, Graz, 2010.

[3] Adelaja, A.O.; Damisa, O.; Oke, S.A.; Ayoola, A.B; Ayeyemitan, A.O. A Survey on the Energy Consumption and Demand in a Tertiary Institution. Maejo International Journal of Science and Technology 2008.

[4] Ogedengbe, E.O.B.; Kraehling, D.; Adem, Z.A. Demand Side Monitoring of Energy Systems in Onatario's Residential and Commercial Sectors. $9^{\text {th }}$ Annual International Energy Conversion Engineering Conference AIAA 2011-5871, 31 July - 03 August 2011, San Diego, California.

[5] Etiosa, U. Energy Efficiency Survey in Nigeria, A Guide for Development Policy and Legislation. Community Research and Development Centre 2009.

[6] Ogedengbe, E.O.B.; Naterer, G.F. Convective Flux Dependence on Upstream Flow Directionality in Finite Volume Computations. Numer. Heat Trans., 2007, 51(7), 617-633.

[7] Liang, H.; Lin, T.; Hwang, R. Linking Occupants' Thermal Perception and Building Thermal Performance in Naturally Ventillated School Buildings. App. Energ., 2012, 94, 355-363. 
[8] Orosa, J.A. Research on general thermal comfort models. European J. Sci. Res., 2009, 27(2), 217-227.

[9] Linden, W. V.; Loomans, M.; Hensen, J. Adaptive Thermal Comfort Explained by PMV. Proceedings of the $11^{\text {th }}$ International Conference on Indoor Air Quality and Climate, Copenhagen. International Centre for Indoor Environment and Energy, Technical University of Denmark. 2008

[10] Cheng, Y.; Niu, J.; Gao, N. Thermal Comfort Models: A Review and Numerical Investigation. Build. Environ., 2012, 47, 13-22.

[11] ANSI/ASHRAE STANDARD 55-2004. Thermal Environmental Conditions for Human Occupancy. Am. Soc. Heat., Refrigeration and Air Conditioning Engineers 2004.

[12] Schellen, L.; Loomans, M.G.L.C.; Kingma, B.R.M.; de Wit, M.H.; Frijns, A.J.H.; van Marken Lichtenbelt, W.D. The Use of a Thermophysiological Model in the Built Environment to Predict Thermal Sensation Coupling with the Indoor Environment and Thermal Sensation. Build. Environ., 2013, 59, 10-22.

[13] Homod, R.Z.; Khairul, S.M.S.; Almurib, H.A.F.; Hagi, F.H. RLF and TS Fuzzy Model Identification of Thermal Comfort Based on PMV/PPD. Build. Environ., 2012, 49, 141-153.

[14] Kalz, D.E.; Pfafferott, J.; Herkel, S.; Wagner, A. Building Signature Correlating Thermal Comfort and Low-Energy Cooling: In-Use Performance. Build. Res.Info., 2009, 37(4), 413-432.
[15] Fanger, P.O. Thermal Comfort Analysis and Application in Environmental Engineering, McGraw-Hill Book Company, 1972.

[16] Ismail, A.R.; Jusoh, N.; Rahman, M.N.; Zulkifi, R.; Kardigama, K. Thermal Comfort Assessment at Parcel and Logistic Industry: A Field Study in Malaysia. Instit. Eng., 2011, Malaysia, 73(3).

[17] Kumar, A.; Singh, I.P.; Sud, S.K. An Approach Towards Development of PMV Based Thermal Comfort Smart Sensor. Int. J. Smart. Sens. Intell. Syst., 2010, 3(4).

[18] Djongyang, N.; Tchinda, R.; Njomo, D. Thermal Comfort: A Review Paper. Renew. Suitain. Energ. Rev., 2010, 14, 2626-2640.

[19] Carlucci, S.; Pagliano, L. A review of indices for the long-term evaluation of the general thermal comfort conditions in buildings. Energ. Build., 2012, 53, 194-205.

[20] Schweiker, M.; Shukuya, M. Adaptive comfort from the viewpoint of human body exergy consumption. Build. Environ., 2012, 51, 351-360.

[21] Sourbron, M.; Helsen, L. Evaluation of Adaptive Thermal Comfort Models in Moderate Climates and their Impact on Energy Use in Office Buildings. Energ Build., 2011, 43, 423-432.

[22] Mansour-Al, Sadi, Design and Building of Biogas Digester for Organic Materials Gained from Solid Waste. M.Sc Thesis, AhNajah National University, Nablus, Palestine 2010.

(C) Ogedengbe et al.; Licensee Bentham Open.

This is an open access article licensed under the terms of the Creative Commons Attribution Non-Commercial License (http://creativecommons.org/licenses/by-nc/3.0/) which permits unrestricted, non-commercial use, distribution and reproduction in any medium, provided the work is properly cited. 